\title{
Learner Support in the Open Distance Learning and E-Learning Context Using the Community of Inquiry Model
}

\author{
Baloyi GP \\ University of South Africa, College of Education; Department of Adult Basic Education and Training \\ Email: baloygp@unisa.ac.za
}

\section{Doi:10.5901/mjss.2014.v5n20p1251}

\section{Abstract}

The recent global growth and popularity of Open Distance Learning (ODL) have been attributed to its advantages, such as flexibility for students who wish to study while working. Moreover, ODL is an effective tool in extending participation to students from less privileged social groups who are unreachable due to geographic location or who cannot access higher education due to diverse factors, such as financial constraints or domestic arrangements. In the light of this, this study investigated learner support in the Department of Adult Basic Education and Training (ABET) at the University of South Africa (Unisa), the largest, dedicated ODL institution in South Africa. A literature study identified the Community of Inquiry (Col) model proposed by Garrison, Anderson and Archer (2000) as useful in this context, and the model will be used as a conceptual framework for the empirical inquiry. The researcher drew a random sample of 400 students $(n=400)$ from a total number of 1808 students enrolled for the Higher Diploma in Adult Basic Education and Training. A quantitative research approach was employed to investigate the research questions. The Col framework proposes that successful learning takes place when there are three presences in a class, namely social, teaching and cognitive presences (Garrison et al. 2000). The study will focus on the social presence aspect of the model. The Col theoretical framework represents a process of creating a deep and meaningful (collaborative-constructivist) learning experience. According to Engelbrecht (2003:39), e-learning models provide valuable frameworks for understanding the integration of technology and pedagogy, and may help to identify key disparities between the current and desired situation. Given the access and communication facilities of the Internet, an e-learning environment has distinct advantages as a means of providing support for communities of inquiry in order to promote higher-order learning. The majority of the students $(66,1 \%)$ feel comfortable talking to one another during teaching and learning. The students use myUnisa to talk about the teaching and learning activities. The findings here are that students use myUnisa to communicate comfortably among themselves. There is student-to-student interaction and this promotes learner-centredness.

Keywords: Open Distance Learning (ODL), University of South Africa (Unisa), learner support, Adult Basic Education and Training $(A B E T)$, online learning.

\section{Introduction}

The concept of Open Distance Learning (ODL) is very broad and can be defined in various ways; hence it is important to point out that there is no single, all-embracing definition. Freeman (2004:6) defines ODL as an amalgamation of two approaches which focus on expanding access to learning. Research by Moon, Leach and Stevens (2005:218) define $\mathrm{ODL}$ as the open learning approaches which, when combined with distance education methodologies, are often referred to collectively as open and distance learning. According to Commonwealth of Learning (2000), ODL is "correspondence, home study, independent learning ... flexible learning or distributed learning". In ODL philosophy and practice, ODL represents approaches that focus on opening access to education and training provision, freeing learners from constraints of time and place, and offering flexible learning opportunities to individuals and groups of learners (UNESCO 2002:7). Common elements on which many authors agree in their definitions are the combination of Distance Education (DE) and Open Learning, and access and separation between the lecturer and the learner.

In general, the goal of ODL is to broaden participation and to overcome geographical, social and economic barriers (Kelly \& Mills 2007:49). The Ministry of Education in South Africa has identified ODL as a system that should extend educational opportunities and provide access for individuals who do not have the opportunity to study full-time. The National Plan for Higher Education (DoE 2001) advocates an increase in the general participation rate in public higher education in South Africa, with the aim of facilitating lifelong learning, developing the skills base of the country, and redressing historical inequities in the provision of education. Other policies and reports promulgated to make ODL a reality are those of the DoE (1996), the Council on Higher Education (CHE 2002/2004) and the National Council of Higher Education (NCHE 1996). Badat (2005) adds that, through ODL, access is given to people who would not have the 
opportunity to study full-time because of work commitments, personal and social circumstances, geographical distance, or poor-quality or inadequate prior learning experiences. The South African government aims to broaden the participation rate in higher education, even in remote rural areas. In ODL contexts, lecturer and learner are at a distance from each other. Consequently, learners experience isolation due to separation from their institution, lecturers and fellow students (Rumble 2000:1). ODL has been successful in increasing the number of students, but unsuccessful in obtaining satisfactory throughput rates. Part of the reason for this is that students are isolated from their teachers, and some students are unprepared for higher-education studies.

The study investigates the provision of learner support in the Adult Basic Education and Training (ABET) programme at a specific university, the University of South Africa (Unisa). Extensive literature has been reviewed on the development of ODL as a mode of higher-education provision, the characteristics of ODL, the rationale for ODL provision, the use of Information and Communications Technology (ICT) in ODL, learner support in ODL, and the state of ABET in the South African and Unisa contexts.

Unisa has been identified by the Ministry of Education as an ODL institution that should help in broadening participation. However, the other ODL institutions are faced with a number of challenges, including dropout, learner support, etc. Makina (2008:1) suggests that, although ODL has been acclaimed for providing access to higher education for students previously denied this privilege, this formal admission has not been matched with adequate learner-support strategies to ensure success. It is in this context that the researcher undertook the research project so as to explore these claims further.

ODL students often feel isolated, as they are studying on their own. Boyle, Kwon, Ross and Simpson (2010:122) state there can be particularly acute issues in the distance learning environment where students often report feelings of isolation, little sense of connection and belonging, and are challenged to maintain engagement in, and motivation for, learning.

Perraton (2000) argues that ODL institutions have high dropout and low pass rates. Yet, according to Daniel, Kanwar and Uvalic-Trumbic (2009:24), ODL is an effective way of reaching out to large student numbers.

Against this background, this study investigated Unisa's ODL system with specific reference to the provision of learner support and an ABET programme.

One of the critical components in ODL is learner support. Learner support has frequently been identified as particularly important for student success in ODL. According to Simpson (2002), Tait (2000) and Thorpe (2002), learner support is a broad term referring to the services provided for distance learners so that they can overcome barriers to learning and complete their studies successfully.

Learner support is defined in different ways in the distance and online learning literature (Brindley, Walti \& Zawacki-Richter 2004). It might cover learning materials, teaching and tutoring, non-academic elements, administrative aspects, guidance and counselling. In this study, "learner support" refers to all kinds of services, including face-to-face teaching during group discussions or tutoring. Dzakiria (2005:95) and Kelly and Mills (2007:149) add that learner support has frequently been identified by open learning institutions as being of particular importance for student success in ODL. All these scholars are of the view that learner support is learner-centred and crucial for learner success in ODL.

In 2008, Unisa introduced an ODL policy which changed the focus of tuition to include technology and multimedia interaction. In responding to the global call, Unisa uses various technologies to reach out to its students and provide them with opportunities to learn through the various technologies. The e-learning model was introduced in 2013 to strengthen the policy and to continue to reach out to the majority of students. However, a number of challenges face Unisa lecturers and students in using the learner-support systems to reach out one another. Anderson (2008) and Aluko, Fraser and Hendrikz (2011) argue that ICT can enhance traditional learner-support systems.

According to Chen and Chen (2008:12), it is widely recognised that distance education through technology has the potential to provide access at reasonable cost by sharing the quality education resources developed and used in the major cities.

These and other views presented above influenced the researcher to undertake the research project.

\section{Conceptual Framework}

This study is a descriptive and interpretive case study of learner support in the specific ODL context of the ABET programme. The Community of Inquiry (Col) model, originally proposed by Garrison, Anderson and Archer (2000), served as an additional conceptual framework for the study. The framework has been adopted and adapted by researchers worldwide and used to inform research and practice online and blended learning (Swan \& Ice 2010).

The researcher used this model as a guide for the empirical study of learner support at Unisa. According to Peters 
(2000), theory is essential for understanding reality. It is a unit of knowledge that comprises facts, assumptions and hypothesis. Garrison et al. (2000) state that a "theory is a coherent and systematic ordering of ideas, concepts and models, with a purpose of constructing meaning to explain, to interpret, to shape practice".

\section{Statement of the Problem}

According to Rumble (2000), distance education institutions have been instrumental in developing support services that will assist their students to perform. The focus on providing learner-support services has been driven by the need to address the high dropout rates associated with correspondence education. One of the major challenges facing distance education institutions is to provide support for "isolated students who are left to fend for themselves" (Brindley \& Paul 2004:40). Distance education students are separated from the lecturers. The distance between the students and the institution is a worrying factor. The effects of such isolation on distance learners can inhibit any possibility for engagement with teachers, study material and peers (Simpson 2002). The literature reviewed shows that such isolation of distance students can be remedied by proper provision of learner support (Simpson 2002).

Moore (2012:167) maintains that, ideally, all students should receive some sort of orientation when they enter a programme. This, too, will reduce the need for individual counselling later. It is particularly important to inform people of the time demands that accompany distance learning and to encourage them to think about how they will fit the work in with their interests and obligations. According to Anderson (2008), an understanding of students, their learning environment, and their cultural attributes is a prerequisite for the development of -student-centred support services.

In the South African context, various government policy papers have, since 1994, outlined a number of strategies to redress the imbalances created by the apartheid system. According to the CHE (2004), one of these strategies has been to improve access for poorer students to institutions of higher learning. According to the 1995 National Commission Distance Education Report, distance education institutions have not been successful in enabling learners to perform to their maximum potential. This is a challenge to ABET students. Glennie and Bialobrzeska (2006) emphasise that, in correspondence education, distance education students sometimes receive study material in the form of only a wraparound to a textbook, which they must purchase separately, and their next engagement with the institution is when they sit for the examination.

The National Council of Higher Education Report (1996) cited distance education as a critical player in redressing the imbalances of the past by removing barriers to access and success. The Ministry of Education in South Africa reported: "These dropout rates are unacceptable and they represent a huge wastage of resources, both human and financial ... and are likely to be an impediment in achieving the economic development goals of the Government" (DoE 2001:21).

Badat (2005:202) warns: "Unless serious attention is paid to the quality of distance education provision programs, equality of opportunity and outcomes of historically disadvantaged students will be compromised as students graduate with underdeveloped knowledge, competencies and skills." This presents challenges for ABET students in the Department, as the majority of them come from the rural provinces of South Africa.

To provide support for its students, Unisa has built learning centres in the provinces of South Africa. However, the majority of the ABET students are in rural areas and struggle to access the resources of learner support provided for them by the University. The ABET Department is concerned about addressing the inequalities that exist, especially in rural areas. Therefore, it is imperative to make learning in the Department student-centred.

According to Qakisa-Makoe (2005:44), learners, like everybody else, need support as they go through life, especially when going through the big challenge of attending a university. The purpose of learner support is to guide and support students to succeed in their studies. University education seems to be a challenge for diverse ABET students, who, as has been indicated, mainly come from rural areas. Moreover, they come from rural areas where there are poor teaching and learning resources. The 2001 National Plan for Higher Education states that higher-education institutions must increase access for previously disadvantaged people in order to redress past inequalities.

The ABET students come mainly from the rural Eastern Province and Limpopo. Unisa seems to be the only ODL institution in South Africa which caters mainly for students who come from rural areas.

Qakisa-Makoe (2005:43) states that most of Unisa's African students come from homes where they are firstgeneration learners in the sphere of higher education and are expected to learn completely new material independently and to adjust to new ways of learning in a distance learning environment.

This is the problem the researcher wishes to address in this paper. The importance of learner support in ODL is crucial and many scholars reviewed above argue that it has a role to play in increasing the success rate of the students. The relatively low pass rate and the dropout rate are a cause of concern for Unisa. The enrolment of ABET students has 
declined in recent years. Although global best practice is employed at Unisa, multiple challenges face the students and lecturers regarding learner support. Unisa uses technology to reach out to its students who are in urban and rural areas. However, students and lecturers are faced with problems in using technology for teaching and learning. This prompted the researcher to explore the perceptions, views, opinions and attitudes of the ABET students concerning the use of learner-support structures. The learner-support structures at Unisa depend on ICT, tutorial classes, group discussion classes, etc.

The main research question identified in this study project was formulated as follows:

How do ODL systems at the University of South Africa provide for learner support in an ABET programme? To address the research question, it was imperative to answer the following sub-question:

- What recommendations can be made for the improvement of learner support at Unisa in general, and for ABET students in particular?

\section{Aim and Objectives}

The main aim of the study was to investigate how ODL systems at the University of South Africa provide for learner support. Objectives of the study were as follows:

- To investigate common theories of, and approaches to, learner support in the ODL context, as presented in the literature.

- To explore ABET lecturers' and students' experiences at Unisa regarding the use of learner-support strategies and to investigate challenges.

- To identify common barriers which impede the use of online technologies for learner support and learning.

- To offer recommendations for the improvement of learner support for Unisa students in general, and for ABET students in particular.

\section{The Researcher's Position}

The researcher completed his studies at Unisa while teaching at primary and secondary schools in Limpopo. Other relevant work experience includes positions held by the researcher as a tutor in Teacher Education at the University of the North-West, and currently as a lecturer working in the ABET Department at Unisa. Thus the researcher has had personal experience, as a student and as a lecturer, of ODL instruction and its related challenges.

\section{Significance of the Study}

Against the background given above, the study is significant for the following reasons. The literature reviewed indicates that ODL focuses on removing barriers to accessing higher education, particularly with regard to students who live in disadvantaged and rural areas where learner support is central to student success (Badat 2005; Dzakiria 2005; Kelly \& Mills 2007; Thorpe 2002). The study was informed by methods of learner support through e-learning in general and makes suggestions for the appropriate use of ICT in providing learner support for ODL in all departments at Unisa.

\section{An Overview of the Research Design}

The research project follows a case study design. The case study approach is not a method as such, but a research strategy in which the researcher aims to study one case in depth (Burton \& Bartlett 2009:63). The researcher used quantitative and qualitative research methods to investigate the experiences of Unisa students registered for the Higher Diploma in Adult Basic Education and Training (ABET). No hypothesis was formulated for the study. The research project was both explorative and descriptive and aimed at exploring strategies, since the aim was one of improving support for ODL students.

O'Leary (2004:159) claims that the quantitative method refers to the research design, which is structured, predetermined and formal, with the specific questions being rigid once empirical investigations start. It uses experiential techniques and research methods that generally include questionnaires. On the other hand, qualitative methods gather in-depth and elaborate information from a small, personally sampled group of people. The two methods were used to support each other in the present study.

Phase one (the quantitative component) comprised a survey of students' opinions and the challenges faced by 
them. The researcher drew a random sample of 400 students $(n=400)$ from a total number of 1808 students enrolled in the Higher Diploma in Adult Basic Education and Training. Owing to financial and time constraints, it was not possible for the researcher to include the entire population enrolled for the course. The sample was representative of the following racial groups: African, Coloured, Indian and white. A standardised questionnaire was mailed to the respondents and comprised mainly closed questions, with a limited number of open-ended questions. This questionnaire covered a wide range of topics on learner support. Advantages of the questionnaire were that it could be mailed to students and that standardised questions were easily quantifiable.

In Phase two (the qualitative component), the researcher used purposive sampling. The sample comprised 15 ABET students and 10 lecturers teaching in the ABET Department at Unisa. McMillan and Schumacher (2006:319) explain purposive sampling as the strategy of selecting information-rich cases for in-depth study. Thus, in this study, the researcher sought participants who were judged to be able to respond regarding the issues raised by the research question. Research by Gorard (2001:10) indicates that the purpose of sampling in qualitative research is to use a relatively small number of cases to find out about a much larger number of issues. In semi-structured interviews, the researcher spoke to participants face to face according to an open-ended interview guide.

\subsection{Data analysis}

The data from the completed questionnaires was analysed by the researcher with the help of the statistician from the Bureau of Market Research at Unisa. The SPSS statistical package was used to analyse data captured from questionnaire responses. The analysis undertaken included frequency tables, means calculations, graphs and the Cronbach Alpha. According to Punch (2003:64), a description analysis of all the main variables is done by focusing on distribution statements. Tables were used to present the results.

The researcher recorded, transcribed and analysed the in-depth interviews. At the end of the interviews, the audio tapes were transcribed and the data examined for key issues raised by participants in response to each topic. From the key issues, patterns were noted and data was categorised and discussed accordingly. Qualitative data from the interviews which corresponded with the survey, was integrated. Patterns emerging from the data were noted and findings were interpreted.

\subsection{Reliability and validity}

The scale reliability and Cronbach Alpha coefficients validating the internal consistency reliability of the six constructs investigated in respect of different teaching presences and learner support in ODL, were calculated. The reliability coefficient of the various presences and support of the constructs was above, 8 , which indicated that the questionnaire tool was highly reliable.

Lastly, the findings from the data collected were compared and integrated to achieve the aim of the study.

\subsection{Findings and discussion}

The findings for Section A (Questions 1 to 8), which deals with the biographical data of the respondents, are summarised in this section.

The respondents were scattered throughout the nine provinces of South Africa. The vast majority of the respondents lived in the rural areas. There were more female students than male students. This suggests that female students have sufficient time to study at home in spite of their domestic schedules. Interestingly, it would have been expected that men had more time owing to less commitment to domestic duties.

The majority of respondents $(99,2 \%)$ were Africans; $0,8 \%$ of the respondents were Coloureds and Indians combined.

Most of the respondents were women (84\%), with only $16 \%$ being men. The diploma course had more female students than male students. This means that the challenges of illiteracy are greater in rural than in urban areas. The majority of students were from the Eastern Cape and Limpopo, which are mostly rural provinces. There is a high illiteracy rate and development is minimal.

The majority of respondents were Africans from mainly the rural areas; most of them come from a poor background and disadvantaged schooling system, and have limited proficiency in English as the medium of instruction.

This means that female students are more concerned about the problems of illiteracy in the rural areas than are the male students. They use the ABET programme to regain the time they lost during the apartheid era. During the 
apartheid era, there was no compulsory education in South Africa. This impacted more on women than men.

The majority of the respondents were from the Eastern Cape $(67,2 \%)$, followed by Limpopo $(8,6 \%)$, Gauteng $(8,2 \%)$, KwaZulu-Natal (5,5\%), Mpumalanga (3,5\%), North West $(2,7 \%)$, Free State $(2,3 \%)$, Northern Cape $(1,6 \%)$ and Western Cape $(0,4 \%)$. The ABET students are scattered mainly in the rural areas of South Africa. The Eastern Cape and Limpopo have more rural areas than any other provinces in South Africa.

\subsubsection{Learner support}

Learner support is developed in order for students to communicate with the University. The question that was asked was designed to find out how they were communicating with the University. The learner support is provided so as to enhance communication between the students and the University. The function of learner support entails providing the students with as much assistance as possible in order to enable them to overcome difficulties that are often encountered by distance education students. Learner support takes on different forms, including the following:

\subsubsection{Group discussion classes}

The respondents attended discussion classes, facilitated by their lecturer during the academic year, as follows: $55,4 \%$ attended once; 8,2\% attended twice; 10,8\% attended three times; 7,8\% attended four times; and 17,7\% attended five times. The ABET Department used to have two group discussion classes before 2009, that is, one during the first semester and another during the second semester. This Department has not conducted group discussions since 2010, when ABET became an academic department. The ABET modules are linked to tutors as another way to support students. The respondents seemed not to differentiate between group discussions and tutorial classes. The majority of respondents viewed tutorial classes, which are held monthly, as group discussions.

Table 1: Internet accessibility

\begin{tabular}{|l|c|c|c|}
\hline Uses of the Internet & \multicolumn{2}{|c|}{ Frequency } & Percent \\
\hline Internet access & Yes & 57 & 22,2 \\
\hline & No & 196 & 76,3 \\
\hline Downloading study material & Yes & 66 & 25,7 \\
\hline & No & 186 & 72,4 \\
\hline Sending and receiving e-mails & Yes & 80 & 31,1 \\
\hline & No & 172 & 66,9 \\
\hline
\end{tabular}

Today, there are many different types of technologies that an institution can utilise in order to facilitate the delivery of teaching and learning. The question asked of students was to what extent they were using myUnisa for learning on a daily basis.

Unisa has an excellent Learning Management System (LMS) in place called "myUnisa". This is an online tool that is available to all registered students who have access to the Internet. Further, it is an asynchronous learning management system. Asynchronous delivery has both advantages and disadvantages, which the researcher discussed in depth in the literature review. Pullen and Snow (2007:143) list as some of its advantages the fact that it is accessible at any time via web pages and that it is interactive. However, as they point out, it is a barrier to students who do not have access to Internet facilities. Using technology facilities like myUnisa makes it possible for the students to learn anytime and anywhere, and to have access to learning resources. The lecturers are able to interact with students at all times. There are also interactive responses between the students and the lecturers.

Table 1 clearly indicates that most respondents $(76,3 \%)$ did not have access to the Internet, with only $22,2 \%$ in fact having access. The question posed sought to establish whether the respondents had Internet access, with particular reference to e-mail - which is the most popular method of communication between students on the one hand and lecturers and the University on the other.

The majority of the respondents $(72,4 \%)$ were not able to download study material from the Internet. Only $25,7 \%$ did actually download study material in this way.

The table also indicates that the majority of respondents $(66,9 \%)$ were not able to send e-mails, but that $31,1 \%$ were able to send and receive e-mails.

The overall response showed that most respondents had no access to the Internet, a factor which would impact their studies and access to learner-support systems. In the Unisa environment, e-mail is probably the most popular communication application of the Internet. It is fast and conveys messages and files within a very short time. 
Unisa is considering the possibility of going online; hence the researcher wished to establish how many students in fact had access to technologies that would make this possible. As a result, it was determined, as indicated above, that $76,3 \%$ of students registered for the ABET programme did not have access to the Internet and lived in the rural areas. Only $22,2 \%$ of the students did have access to the Internet.

In the context of this programme, the majority of students therefore do not have access to the Internet and still rely on print-based materials. Although Unisa wishes to go online and to use the e-learning route, the majority of students in rural areas will be left out of the teaching and learning programme.

Those who have access to the Internet use it for downloading study material, and for sending and receiving emails. Although students can use myUnisa to download learning material, they are not in fact using it. They seem to use it mainly for administration purposes, for example for receiving and sending assignments, etc.

Although the findings in the table suggest that most students do not have access to Internet facilities, students do seem to recognise the value that such access brings to teaching and learning as a means of supporting them.

The students tended to visit myUnisa more regularly. At least 73,5\% reported that they visited the website at least once a week, while $10,5 \%$ indicated that they visited the website more than five times a week. On a weekly basis respondents, visited the Unisa website as follows: once (73,5\%); twice (7,1\%); three times (6,3\%); four times (2,5\%); and five times $(10,5 \%)$.

The majority of the students are using myUnisa for learning. Many of the students reported that they use websites. Most of the students also reported that they access the Unisa website from their mobile phones.

\subsubsection{Study groups}

According to Table 1, the respondents met with their study group on a monthly basis as follows: once $(36,6 \%)$ and twice $(12,2 \%)$.

The question on group discussions was asked to determine if the students understood the difference between such discussions and tutorial classes. In their responses regarding group discussions and tutorial classes, the students tended to confuse the two. The group discussion classes are defined as classes where lecturers meet students at the regional offices and teach them. Tutorial classes, on the other hand, are classes where tutors who are appointed by the ABET Department guide and support students with their assignments. Surprisingly, for most students, group discussions and tutorial classes are the same; hence them reporting three times, five times, etc. Therefore, the majority of the students actually had an incorrect view of what group discussions and tutorial classes entailed. The students also tended to combine direct teaching, facilitation and group discussions. What is clear, however, is that group discussions are effective, because a large number of students actually attend them.

Most students used the library not to obtain resources but as a place to study. Generally, the students regarded the library as a quite place to study. In their home communities, they do not have such a place.

My Unisa could be a useful tool for teaching and learning if it were accessible to students. The students could network and could bridge the distance gap between themselves and the lecturers. The attitude of lecturers to myUnisa was positive. Therefore, they should be encouraged to attend the myUnisa training provided by the University.

My Unisa is consequently benefiting students who have access to the Internet and excluding students who have no access. The lecturer participants could be receiving feedback that comes only from students who have access. Even though myUnisa is regarded as a valuable learning management tool, most participants do not use it for teaching and learning. This claim is also noted by Mabunda (2010:232), who found that participants perceived online learning as benefiting certain groups of students in particular. Apart from recognising that online learning can support distance learning generally, it can also provide access to resources for students who find it difficult to get to the campus. The participants also believed that online learning provided an opportunity for those who found it difficult to take time off work and attend face-to-face discussion classes.

The group discussions were seen as the support structure that could improve teaching and learning in the ABET Department. The participants also confirmed that they had not attended group discussion classes. However, they also stressed that classes were important for promoting teaching and learning activities. The students were in favour of group discussions.

\section{Recommendations}

The Department should consider the local context when implementing learner-support strategies. If we know who the learners are, we will be able to respond to their needs instead of regarding technology as the first consideration. Starting 
from learners' needs prompts more creative and responsive solutions. For example, in cases where there is only limited Internet connectivity in people's homes, or none at all, there may be Internet cafes nearby. An education provider could establish a partnership with the Internet cafes and cover some of the learners' costs in using them, thereby improving Internet access for learners.

The large number of students registered at the University is an indication that, for many students, Unisa is their only access to higher education. Therefore, total commitment to learner support is crucial in this situation. As the only dedicated, comprehensive ODL institution in South Africa, Unisa presents the only opportunity for access to higher education for many students.

The student is always at the centre of what the university or ODL institution should do. Therefore, the ABET Department should move to the next level and discontinue outdated pedagogical practices. The Unisa ODL policies aim to see students embark on a new culture of learning. The ABET Department has to seriously consider other forms of learner support, such as group discussions, tutorials and the radio. Video conferencing, which is still underutilised, is presently not a feasible form because of the challenges faced by students and lecturers.

\section{Conclusions}

Illiteracy rates are higher in rural areas than in urban areas. This is because ABET students come mainly from rural areas. There is also a great number of people in rural areas who have not attended school. Women were identified as the group that needs special attention and motivation in rural areas. The majority of women are tied to children, and this could be the reason why there are more women than men in the ABET programmes who do not proceed to higher education.

Enrolments sometimes have an effect on learning resources owing to the large number of students who need support in rural areas. However, it is important for the Department to cope with the challenges that ABET students are facing.

When distance education institutions fail to plan for the provision of appropriate learner-support services, systematic learning support is adversely affected and the most likely outcome is that distance learners will drop out of their programmes.

\section{References}

Aluko, R.F., Fraser, W.J. \& Hendrikz, J. (2011). Transactional distance theory and total quality management in open and distance learning. Africa Education Review, 8(1):115-132.

Anderson, T. (2008). Towards a theory of online learning. Athabasca University: AU Press.

Badat, S. (2005). South Africa: Distance higher education policies for access, social equity, and social and economic responsiveness in a context of the diversity of provision. Distance Education, 26(2):183-204.

Boyle, F., Kwon, J., Ross, C. \& Simpson, O. (2010). Student-student mentoring for retention and engagement in distance education. Open Learning, 25(2):115-130.

Brindley, J.E. \& Paul, R. (2004). The role of learner support in institutional transformation -a case study in the making. In J.E. Brindley, C. Walti \& Zawacki-Richter (Eds). Learner support in open, distance and online learning environments. Oldenburg: Bibliotheksund Informationsystem der Universitat Oldenburg:39-50.

Daniel, J., Kanwar, A. \& Uvalic-Trumbic, S. (2009). From innocence to experience: The politics and project of cross-border higher education. In J. Fegan \& M.H. Field (Eds). Education across borders: Politics, policy and legislative action. Vancouver: Springer.

Dewey, J. (1933). How we think. Boston MA. DC Heath.

Dewey, J. (1938). Experience and education. New York: Collier.

DoE (Department of Education). (2001). The National Plan for Higher Education. Pretoria: Government Printer.

Dzakiria, H. (2005). The role of learning support in open and distance learning: Learners' experiences and perspectives. Turkish Online Journal of Distance Education, 6(2):1-14.

Garrison, D.R., Anderson, T. \& Archer, W. (2000). Critical inquiry in a text-based environment: Computer conferencing in higher education. The Internet and Higher Education, 2(2-3):87-105.

Kelly, P. \& Mills, R. (2007). The ethical dimensions learner support. Open Learning, 22(2):149-147.

McMillan, J.H. \& Schumacher, S. (2006). Research in education: Evidence-based inquiry. Boston: Pearson.

Moon, B., Leach, J. \& Stevens, M. (2005). Africa Region Human Development. Working Papers Series 104. Designing Open and Distance Learning for Teacher Education in Sub-Saharan Africa: A Toolkit for Educators and Planners. Geneva: The World Bank.

Qakisa-Makoe, M. (2005). Reaching out: Supporting black learners in distance education. Progressio, 27(1 \& 2):44-61.

Rumble, G. (2000). Student support in distance education in the 21 ${ }^{\text {st }}$ century: Learning from service management. Distance Education, 21(2):216-235.

Tait, A. (2000). Planning student support for open and distance learning. Open Learning, 15(3):287-299.

Thorpe, M. (2002). Rethinking learner support: The challenge of collaborative online learning. Open Learning, 7(2):105-119.

UNESCO (United Nations Educational, Scientific and Cultural Organization). (2002). Open and distance learning: Trends, policy and strategy considerations. Paris: UNESCO. 